Hagnetic Susceptibi tity and New ron Diffraction

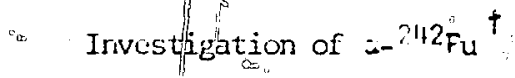

$0^{\circ}=$ Joseph T. Sparks, T. Konoto and billiam J. Fanséy

Law ence Radiation"Laboratory, University of California

Livermore, California 9455

0

\section{" ABSTRACT}

Magnetic susceptibility and ncutron difiraction mieasurements have been mace on a figh purity, polycrystalline sample of $\alpha$-phase ${ }^{242} \mathrm{Pu}$. The susceptibility results show the existence of weak forromanetiun belon " $50^{\circ} \mathrm{K}$. "This suggests that the $\alpha$-phase is antifermagnetic, the observed fermomagnetic monent $\left(9.5 \times 10^{-4}\right.$ em per gram of sample at $4.35^{\circ} \mathrm{K}$ ) originating within antifermonagnetic domain walls." No evidence for antiferromagnetic ordering was observed in the neutron diffraction study suggestirig that tire monent per Fu atom is too small to observe with this techrique."
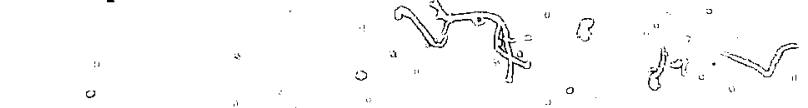

$\sqrt{3}$
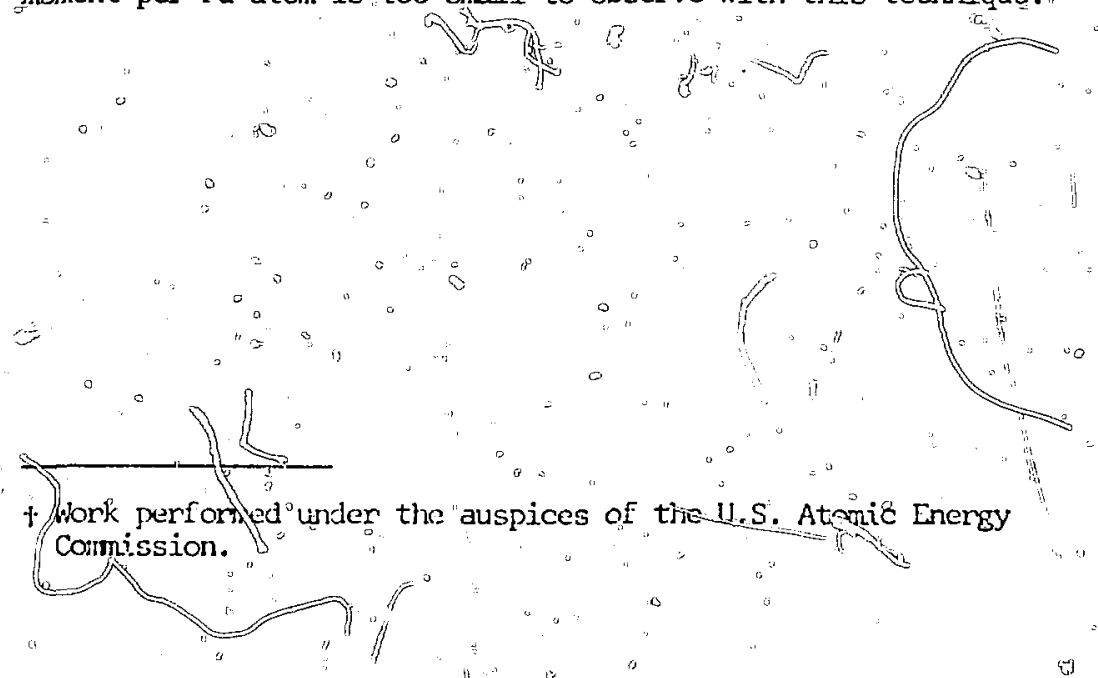

hork perforhed under the auspices of the 11.S. Atamiz Energy 
The question of the existence of a magnetically ondered

state in the alpha plase of plutoniun a: fow tomperature has been a subject of much interest and conjecture for some years. 1-3 poster and Friedel ${ }^{4}$ put forth the hypothesis that $\alpha-\mathrm{lu}$ is antiforromapretic with a liéel temperature around $100^{\circ} \mathrm{K}$ in an attenpt to explain the observed low temperature resistivity anomaly "in terms of spin-disonden scattering "f the conduction electrons. Smoluchoush, 5 hosever, has proposed a wand struature that can account for the resistivity anomaly in terms of interband scattering. "any physical propertics of $\alpha-F u$ have been "measumed" $1-3$ in attenpts to substantiate the mingetic ondering hypothesis. Numerous anomalies have been observed and conflicting results on the same property by different investigators iave been reported. Some of the measurements" suggest magnetic orierins does occun while others appear to refute it. The most direct and unawingous, way to determine if a substance is antifermonagletic on not is by mans of neutron diffraction. The available samples of plutoniun us to nos, however, have had muci too large an effective absorption cross sectica. and were too highly radioactive for good diffraction patterns to be obtained.

Some of the aronalies reported in earlier wonk (e.5., specific heat) are now known to arise from selfinduced radiation danage. $A$ relatively large amount of high purity, electmorefined 242 tu has recently been prepared under the auspices of the U.S.A.S.C. Transm plutonium Program "and the U.S.A.E.C. Isotopes Section. Plutonium samples are therefore non available in which the radiation danage is a minimun. Due to the relatively lon effective absorption cross section of this isotope, neutron diffraction becomes feasifle. "Wie haire made 


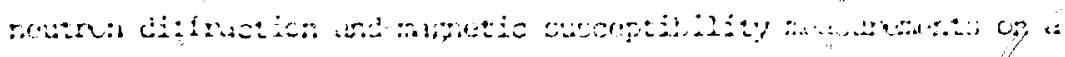

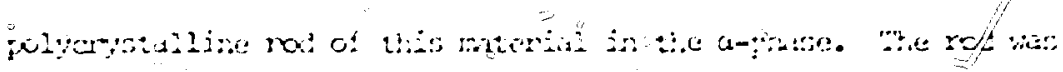

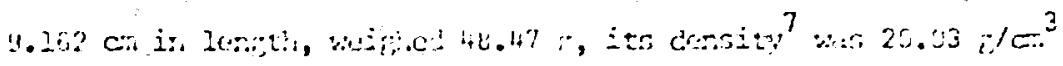

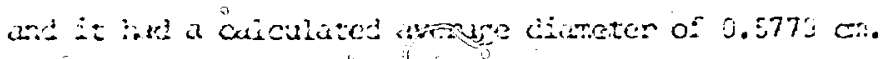

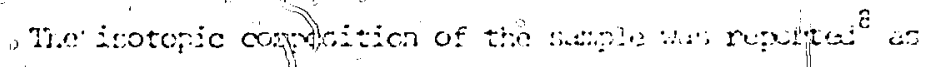

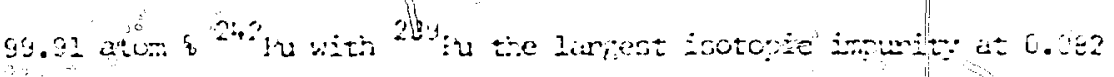

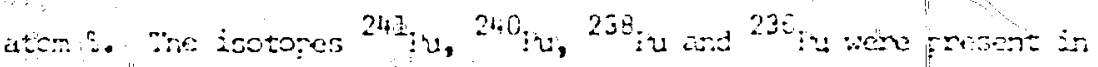

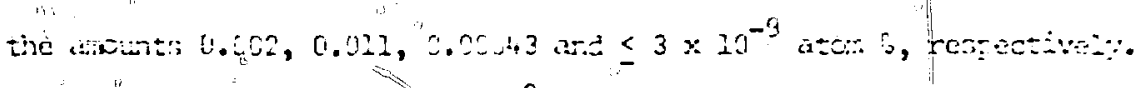

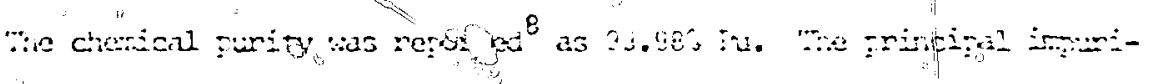

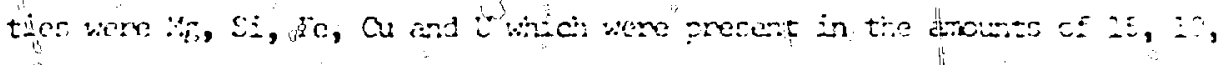

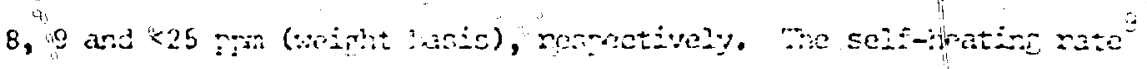

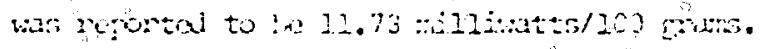

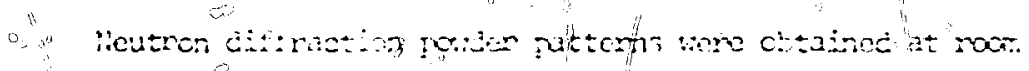

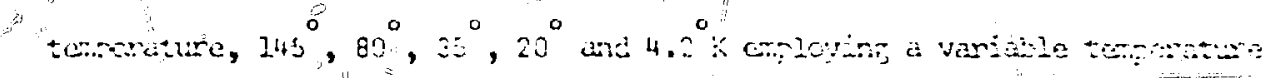

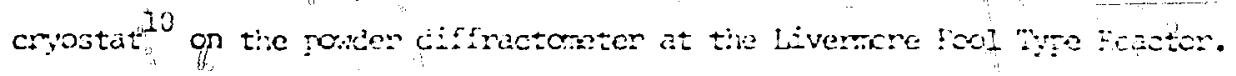

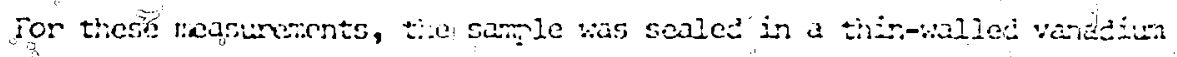

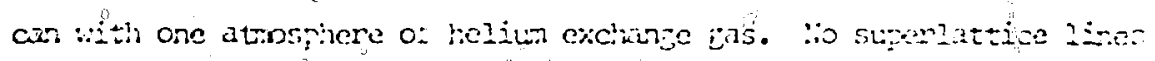

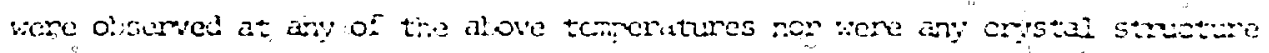

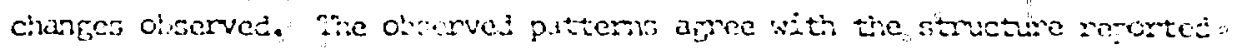

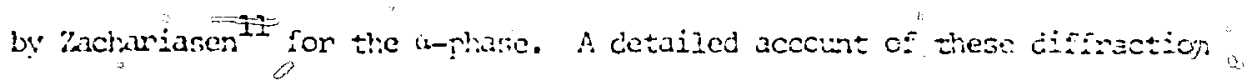

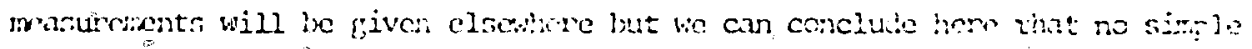

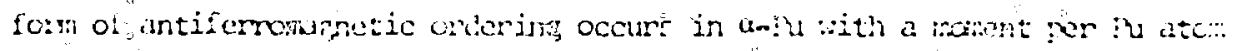

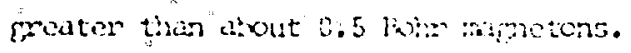

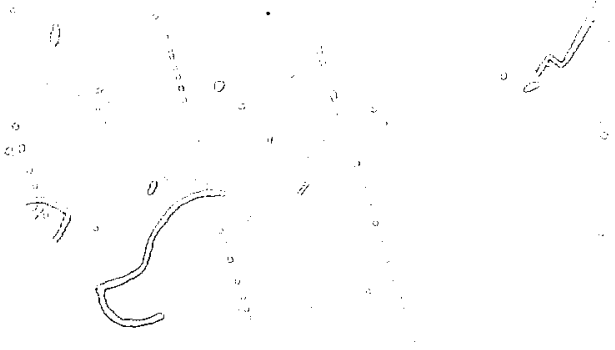




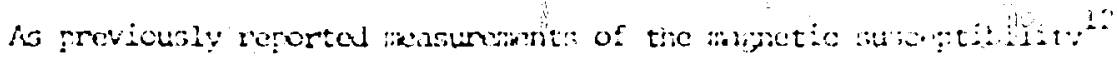

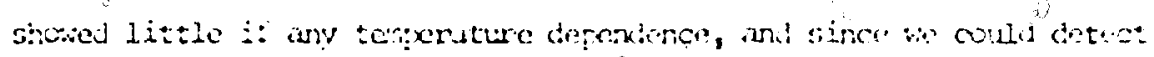

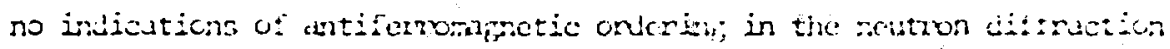

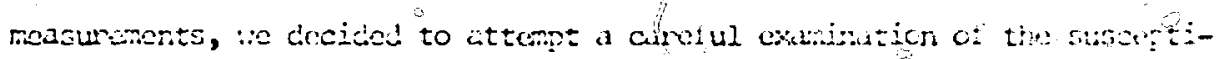

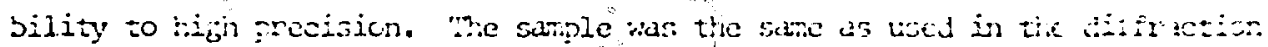

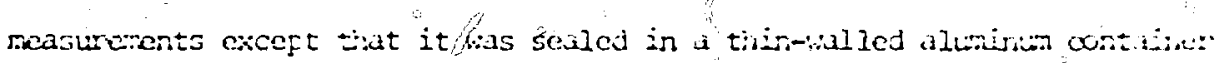

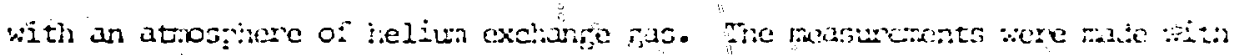

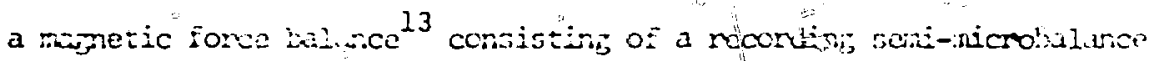

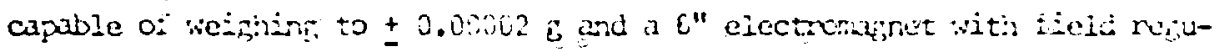
lation and stability hexd to 1 gra by reant of a liall poin roulaton.

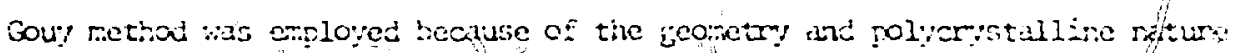

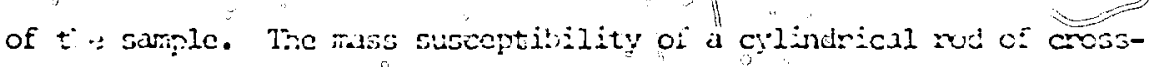

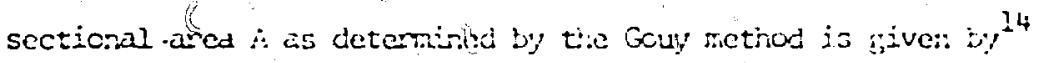

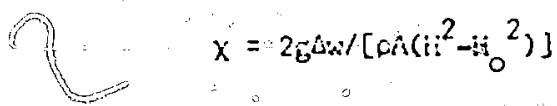

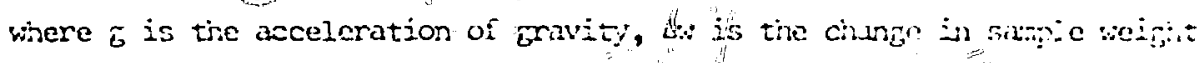

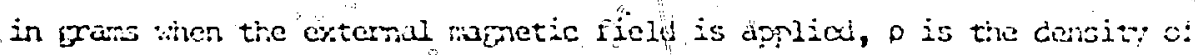
the rod, and it and $h_{0}^{\circ}$ are the vilues of the field at the to exoratios

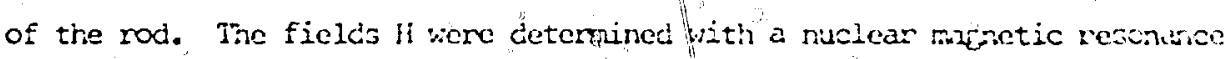

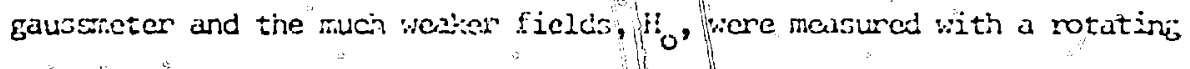
coil Eausancter. The precision to mide $x$ fis deternined derowis en tie

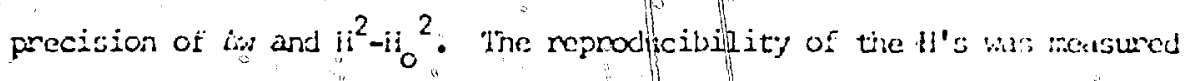

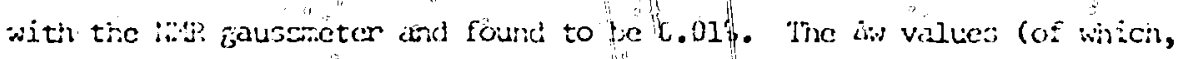

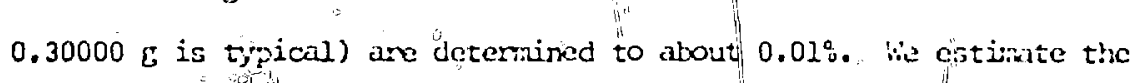

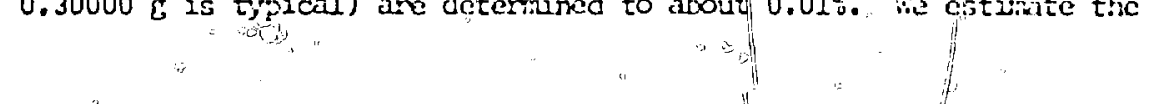




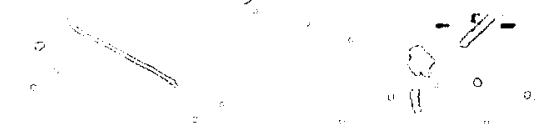

precigion of $x$ tim to be atout 0.04\%. We obtained an experirental is-

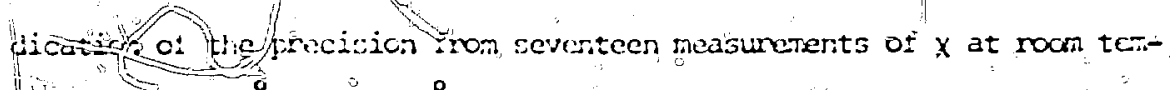
ferstume $\left(295.0^{\circ} \mathrm{k}\right.$ to $297.2^{\circ} \mathrm{k}$ ) in various fields fron 4 to $8 \mathrm{~kg}$. The

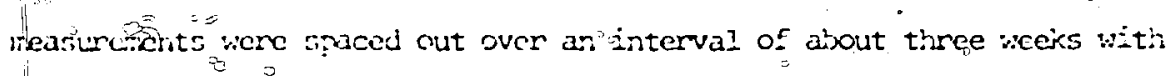

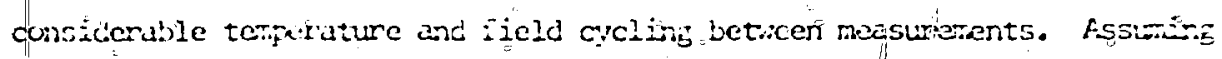

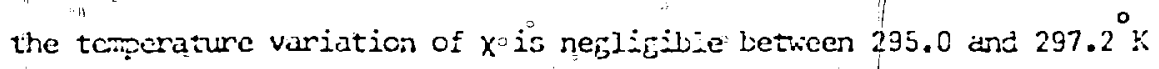
ve aj:ais as averia,e value of

$$
x_{A V}\left(296 \pm 1^{0} \eta\right)=(2.2004 \pm 0.0010) \times 10^{-6} \mathrm{e} / \mathrm{g}
$$

whene the uncertainty here is the stancand deviation This uscertaists is

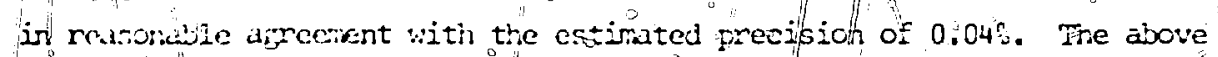
value of $x_{n}$, jus low corrected for the suscentibility of the alturium "simple coption.

" Avariable teiperature cryostat, widh fill be discrized in cetail

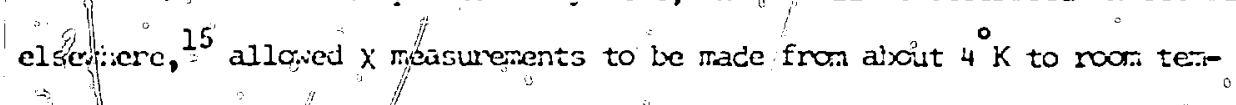
porattre. In this cryostat, the samie is in thermal coniact witi a surroun-

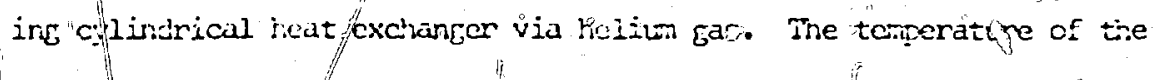
exchanger can be varied by varyine the flon of cold heliun gas on licuic throupitit it. The temperature is measured by a germanium sensor soldeved to we

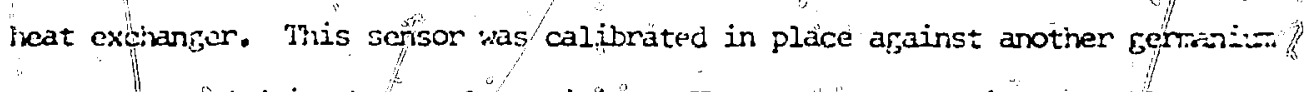
sensor suspended in the sample position. The senson was casily readaille to $0.1 \mathrm{k}$ but the uncertainty in the smple tomperature at lo.s terperatuy/cs, porever, could wo as moch as 2 or $3^{\circ} \mathrm{K}$ because of themal gradicints. 
The field deperdence of any sugcepti.ility measurenent should be detcmined as it his been shom that if a small ingonagretic component is present in the sample the Gouy method gives" 16

$$
x_{11}=x_{\infty}+2 \sigma / H
$$

where $x_{H 1}$ is the susceptibility measured in the field $1, x_{\infty}$ is the suscepcibility at very large fields and $\sigma$ is the saturation mapnetic noment of the ferromagretic component per gram of sample. We have made field dependent measurements at a muber of tomenatures between $4^{\circ} \mathrm{K}$ and roon/ temerature do both the empty aluninum sample holder and on the holder plus Pu sample. Four typical $x_{\mathrm{I}}$ vo $1 / \mathrm{H}$ plots are shown in $\Gamma i_{6} .1$. All values have been corrected for the sample nolder and are this for fy alone. The ficld independence shom by the $294.7^{\circ}$ and $57.0^{\circ} \mathrm{K}$ plots ads obtserved for all temperatures exainined between about $50^{\circ} \mathrm{K}$ ard room temperature. Belon this tomperature, "ield dependence was observed. The "true" paral magnetic susceptibilities, $x_{\infty}$, o5tained by linear extranolation to infinite fielci, are seen to increase by only about $2 \%$ between room temperature and $4.35^{\circ} \mathrm{K}$. The $x_{11}$-values obtainet at $4.35^{\circ} \mathrm{K}$ depend on the magnitude of the extemal applied magnetic field during cool dom. It is interesting to rote that the "true" paramagnetic susceptibility, $x_{\infty}$, at $4.35^{\circ} \mathrm{K}$ is inependent of the value of the field applied during cool corm.

The temperature cependence of $x_{\infty}$ and $x_{H}$ for $H=4$ and $7 \mathrm{kG}$ is shom in rig. 2. The curves belon $50 \mathrm{~K}$ are warming curves. The sample was first cooled to $4.35^{\circ} \mathrm{K}$ in an applied field of $24 \mathrm{kG}$. The external 
ficld was maintained at $14 \mathrm{kG}$ throughout the rarning mus except for the fen minutes it took to make the $\Delta \cdot n$ measurements at 4 and $7 \mathrm{kG}$. The 4 and $7 \mathrm{kG}$ curves in Yig. 2 are comnosites of tro independent runs and illustrate the reproducibility of the data. To obtain reprotucible results it was found necessary to start from above $50^{\circ} \mathrm{K}$ each time, cool dom to $4.35^{\circ} \mathrm{K}$ in some applied field and then to measure $x$ on waming with the cool-dom field applied to the sarple between neasurements.

The ralues of $\sigma$, as determined fron the slope of tine $x_{\mathrm{in}}$ vs $\mathrm{H}^{-1}$ curves, is shown plotted against temerature in Fig. 3. The solid curve is associated with the measurenents of $x_{H}$ in bhich a $14 \mathrm{kG}$ field was applied as described above. Trie results of two independent runs are clearly indicated in this figure. Also tndicated are the values of $\sigma$ cbtained at $4.35^{\circ} \mathrm{K}$ upon cooljhg down thnough $50^{\circ} \mathrm{K}$ with applied fieics ranging from 0 to $10 \mathrm{k}$.

It is clcarly evident in both Figures 2 and 3 that a magnetic transition of some kind is occurirg at about $50^{\circ} \mathrm{K}$. We have constored trurce possibilities to account for this behavicr: (1) the cresence of a ferponasnetic impurity in small concentration, (2) intrinsic fermomatnetisn of plutonium and (3) antiferromagnetism. Even tiough our material is of high chemical Inohty, it is difficult to absolutely nule out impurities "as the source of the hagnetic behivion. However, no knom compounds of plutoniun exhibit miphetic orderits around $50^{\circ} \mathrm{K}$ to cur knosiedpe. he checked for sample honpgeneity by disnlacing the samnle vertically $0.835 \mathrm{~cm}$ with respect to the malsnet and renleasuring $\sigma$ at $4.35^{\circ} \mathrm{K}$. The values of $\sigma$

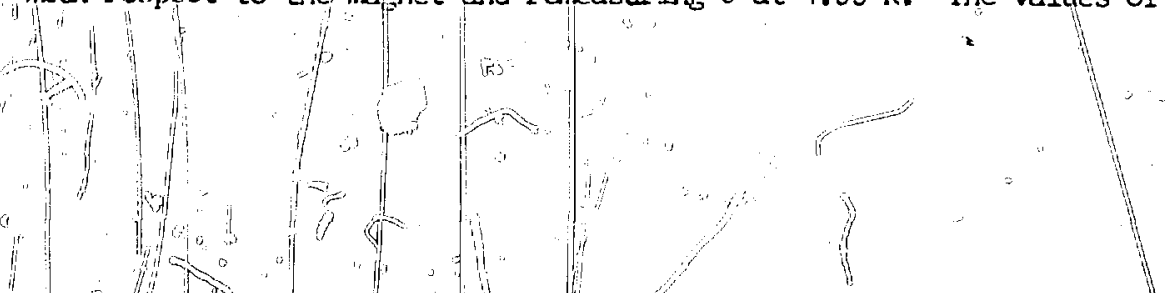


before and after the displacenent adrefe to within $0.1 \%$ indicatiof that the otserved magretic behavion is not due to some localized magnetic inclusion or granule.

If $\alpha-n$ is intrinsically fernomatic, with a Curic tomeratume of about $50^{\circ} \mathrm{K}$, then the calculated monent per Pulan is about $10^{-4}$ bots magnetons. We have little feeling for the possjble existence of such at weak ferromagnetic state, "If, however, $\alpha$-Pu ifs antifermongetic ath al" moment per atan of about 0.3 Boin magnetons aj postulated by fociner and Friedel, ${ }^{4}$ then it is possible that belon $50^{\circ} \mathrm{K}$ we arc observing a net garphic moment assuciated with antifermananetic domain bourdaries as discussed zy $\mathrm{Li}^{17}$ and suggested as the source of the weat ferpomagnetion observed in a- IE If this is the case, then the field depende,t bdhavion of $\sigma$ at $4.35^{\circ} \mathrm{K}$ becomes more easily understandable as the net mone-ts in the aitiforrametic dowain boundaries tend to line up with the applied field. The lenger tine applied field the better this alignment will he and thus the frater the measured "." The small value of $\sigma$ would also be understandable" as onlv a small percentage of the Pu atons rould be involveri in the domain bcungaries. oun negative neutron diffraction results do "not conflict with tisis interpretation. The crystal stmucture of the $\alpha$ phase is pomplicated and mumerous lines are optained in the diffaction pattem abich thes it difficult to see a monent of the size surgested by locher.

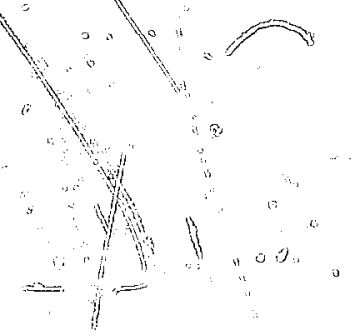




\section{References}

Plutonius 1960, cuited by E. Grison, W. B. H. Lord and R. D. Fonler, (Cleaver-liume iress Ltd., London, 1961 ).

Plutoniun 1965, edited by A. K. Kay and 1. B. Waldron, (Ciaprian and Hall, London, 1967).

${ }^{3}$ Plutonium 9970 and Other Actinidles, edited by W. H. Miner, (The Metallunical (society, lies York, 1970 ).

4. A. Pocter and J. Frieciel, J. Phys. Chen. Solids 18, 196 (1961) and Y. f. Pocher, Adv. Physics 11, 233 (1962).

5.j. Smoluchorski, Mys. Rev. 125, 1577 (1952).

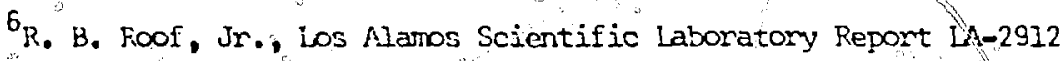
(1963).

T. A. Sandena:, ?. 69 of reference 3.

8.. 3. Hiner (private comunication). T. A. Sandenain (private comunication).

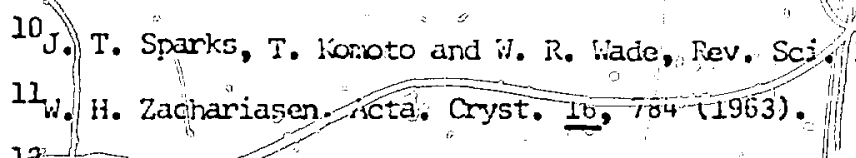

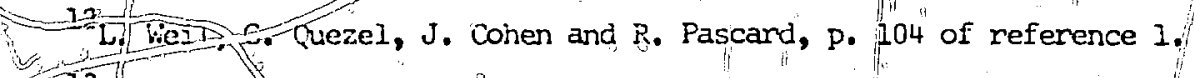
$13 \mathrm{~J}$ T. Sparks and T. Komoto, (to be published).

14L. F. Bates, Bodern larnetisn (Cambridge University Press, 1963), 4hiled., p. 115 .

15J. T. Sparks, (to he published?.

16 E. Vogt, Ann. Physiti, 14, $1(1832)$ and p. 13! of reference 14. $1 \%$ Y. Y. Li, rings. Rev. 101, 1450 (1950).

18H. H. 'Cooper, A. S. Arrott and H. W. Paxton, J. Appl. Phys. 32, 2566 (196I). 


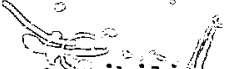

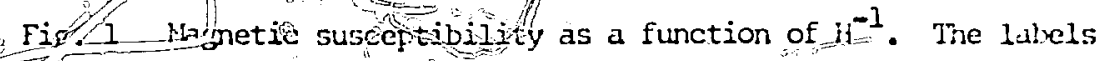
14 and $0 \mathrm{KG}$ on the $4.35^{\circ} \mathrm{K}$ curves refer to the value of the applied external field on coolitig to $4.35^{\circ} \mathrm{K}$.

Fig. 2 Magnetic susceptibility measured at $\mathrm{H}=4$ and $7 \mathrm{kG}$ as a function of $\pi$. These are warming curves obtained after first cooling to $4.35 \%$ in an external field of "1: $\mathrm{kG}$. The $x_{\infty}$ curve is obtained by linear extrapolation of $x_{H}$ vs $H^{-1}$ curves to infirite field. The solid circies indicate field independent foínts.

Fig, 3 The fermananctic moint, determined from the slope of: $\mathrm{X}_{\mathrm{H}} \mathrm{vs}^{\mathrm{s}} \mathrm{H}^{-1}$ curves, as a function of temperature. The numbers on the points at $4.35^{\circ} \mathrm{K}$ refer to the value of the external field (in $k G$ ) applied during the cool dom to $4.35^{\circ} \mathrm{K}$. The circles and triangles are the results of t.o independent sarming runs

S!

\section{NOTLE:}

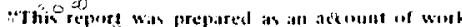

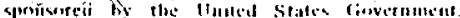

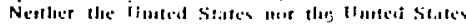

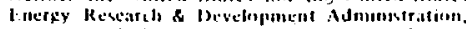

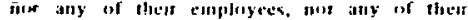

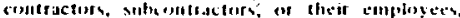
makes ally wirstaty. engress of ampliced. of

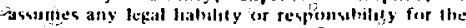
acturacy, completeste'ss or Itsefulness of ally mformation. apparatus.: product or grosess disclened, or cepresents illat itis use nould not infringe privalely owned riglits.: 


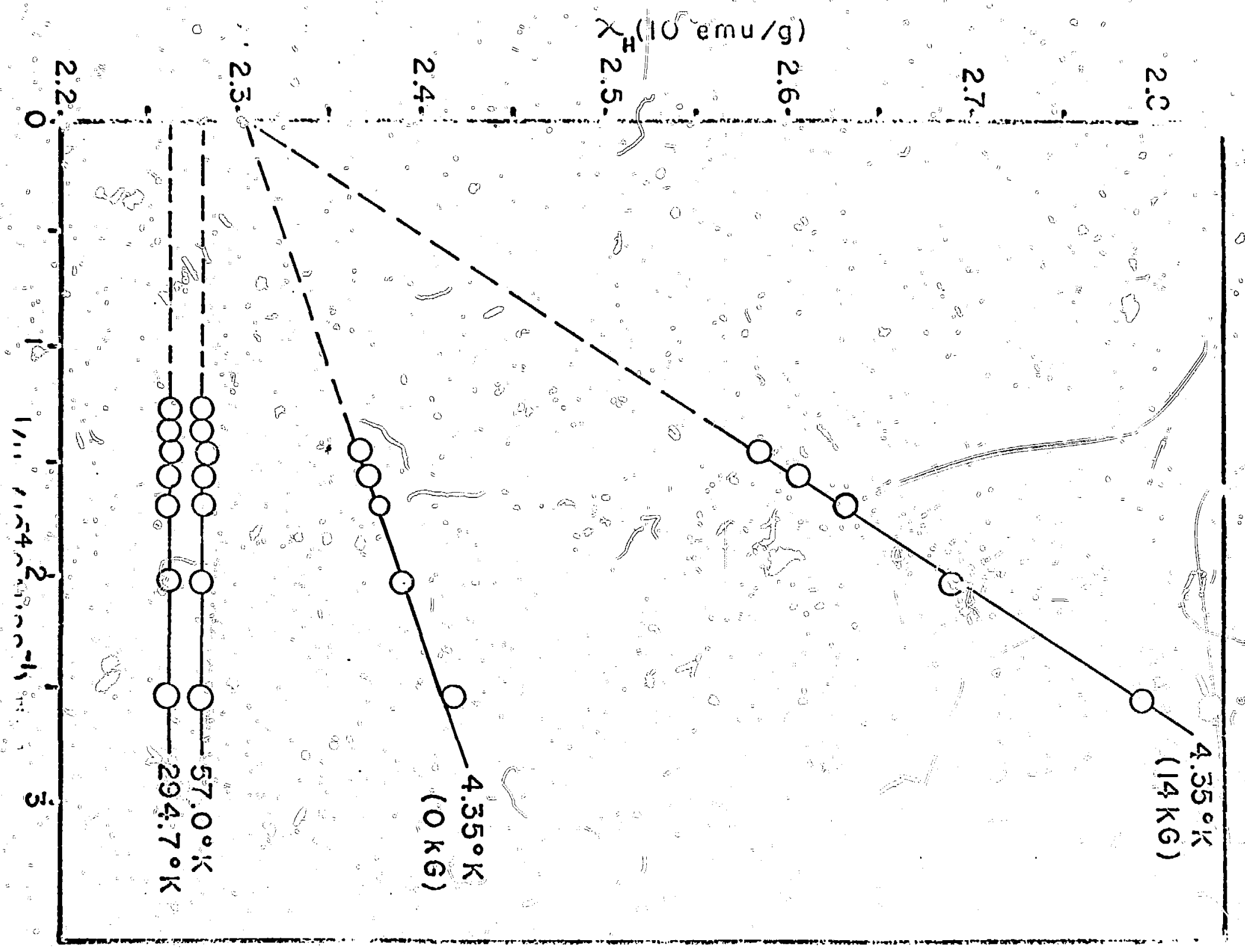





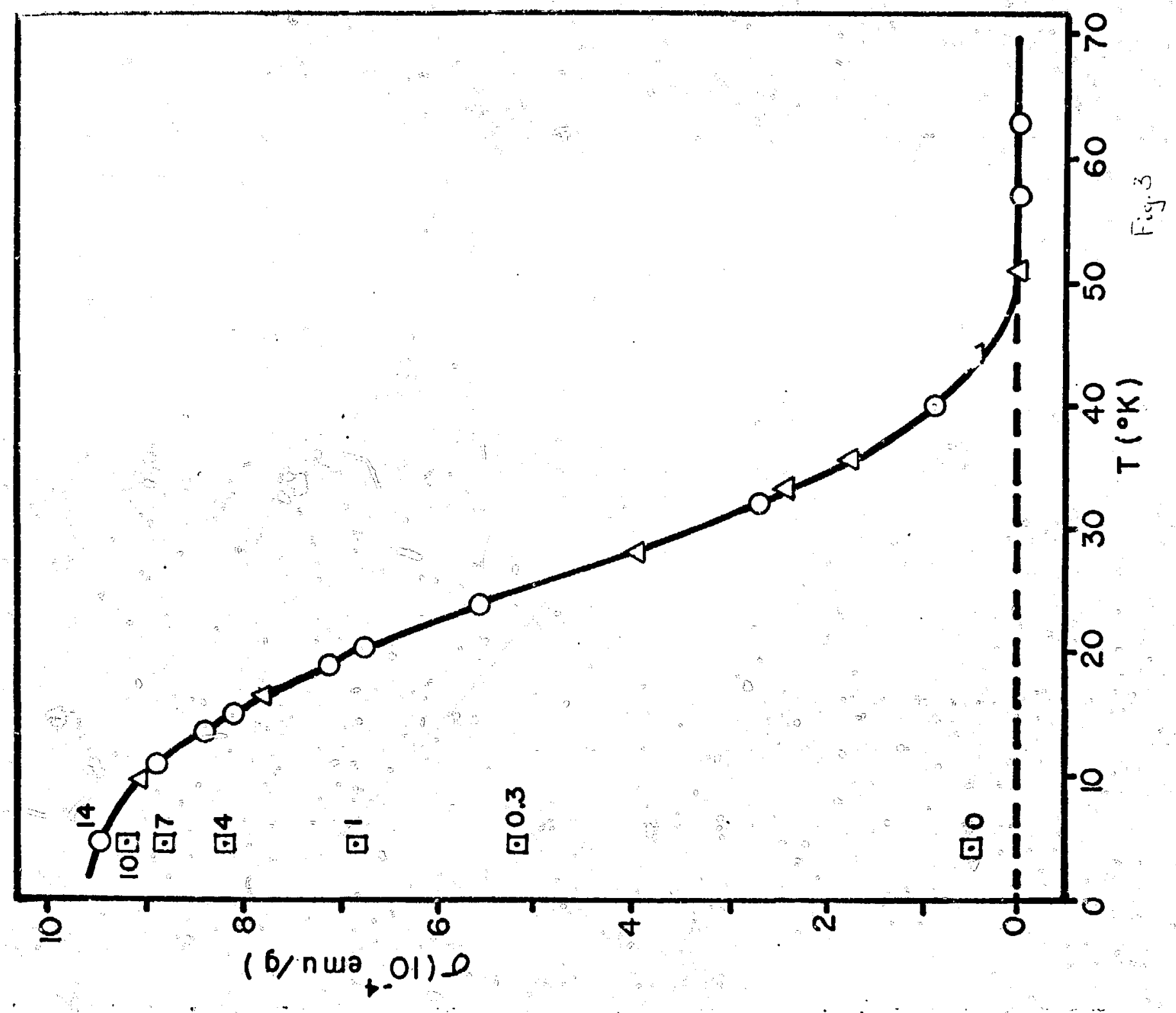

